\title{
Approaches to Investigate the Quality of Life Diagnosis and \\ Management in Infertile Women in the Iranian Health System
}

Fatemeh MIRPARSA ${ }^{a}$, Abasat MIRZAEI ${ }^{a, b}$

aDepartment of Health Care Management, Faculty of Health, Tehran Medical Sciences, Islamic Azad University, Tehran, Iran

${ }^{b}$ Health Economic Policy Research Center, Tehran Medical Sciences, Islamic Azad University, Tehran, Iran

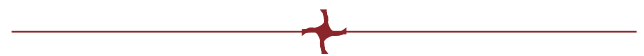

\begin{abstract}
Background: Infertility requires long term care and treatments which would influence different aspects of health, including emotional problems such as anger, depression, mental health and psychological issues, social isolation and withdrawal as well as low self-esteem. The present study was conducted to determine strategies for the diagnosis and management of infertile women's quality of life in the Iranian health system.

Materials and methods: This descriptive-analytical study was conducted on 59 infertile women. It was a questionnaire-based study and all data analyses were done using SPSS version 22 statistical software.

Results: The majority of gynecologists $(88.14 \%)$ approved all three management strategies that were used for diagnosis and management of infertile women's quality of life. The first and third management strategy obtained the highest (86.44\%) and lowest (3.39\%) scores, respectively. There was a significant relationship between our management strategies and the scoring of gynecologists $(P=0.010)$. Also, there was a significant relationship $(P=0.001)$ between the order of our management strategies and gynecologists prioritization.

Conclusion: Based on the results of the present study, it is expected that health officials and practitioners should be able to identify infertile women and even women at high risk of infertility and provide the necessary training and classes as well as individual and medical consultations.
\end{abstract}

Keywords: management strategies, infertility, health system, fertility, quality of life.

\footnotetext{
Address for correspondence:

Abasat Mirzaei, Assistant Professor

Farhikhtegan Hospital, Tehran Province, Tehran, Hesarak, Shohadaye Hesarak Blvd, Iran

Address: District 6, Forsat-e-Shirazi St, Islamic Azad University, Tehran, Iran

Tel.: 989127789006

Email: amacademic@yahoo.com
}

Article received on the $31^{\text {st }}$ of May 2021 and accepted for publication on the $23^{\text {rd }}$ of September 2021 


\section{INTRODUCTION}

I nfertility is one of the greatest stressors in life and results in psychological distress and sexual well-being of women $(1,2)$. In general, infertility is defined as failure to achieve a pregnancy within one year of regular unprotected intercourse. It can be divided into primary and secondary infertility. The first type is when pregnancy did not occur after at least one year of having sex without using birth control methods, and the second type refers to couples who have been able to get pregnant at least once, but now are unable to give birth again. Infertility has various causes, especially a range of psychological problems such as feeling humiliated, anxiety, depression, and feeling of inefficiency (3) that lead to decreased self-confidence and quality of life (QoL). In the past few years, the diagnosis of infertility is increasing (4). About one-tenth of the world's population is infertile. According to World Health Organization (WHO), $43 \%$ of women and $30.7 \%$ of men suffer from secondary infertility (5). The rate of infertility is between $5 \%$ and $30 \%$ in different countries (6). There are no accurate statistics on the number of infertile Iranian couples (7), but a meta-analysis calculated the average infertility rate in Iran to be $10.9 \%(6)$.

The QoL of women with infertility is lower than that of other women of childbearing age (8). Factors that influence the QoL of women with infertility include gender, age, duration of infertility, educational level, marital relationship, fertility expectation, psychological status, and history of assisted pregnancy (8). The quality of life is also one of the main indexes to assess the effects of women and challenges to human fertility arise so health systems have an important role in promoting, maintaining, and rehabilitating people's health and make it possible to achieve optimal health status through good performance and optimal use of available resources (9). The health system at all levels of management needs competent and capable health managers with humanitarian skills. In terms of cost structure of the health system, the move has been to optimize the costs of the health system by introducing a referral system and reducing the share of out-of-pocket payments in providing health system costs. Also, health systems are striving to fulfill their responsibility for ensuring the health of communities by establishing various methods and procedures (10).

The purpose of this study was to investigate the current status of patients' fertility QoL and discuss the factors that influence their fertility QoL as well as the effect of our comprehensive management strategies in treating infertility. $\square$

\section{MATERIAL AND METHODS}

\section{Datients}

Fifty nine infertile women, selected between May 2020 and November 2020, were included in this descriptive-analytical study conducted in Sistan and Baluchestan, Iran. The study protocol was approved by the institutional ethical committee prior to commencement of research and all patients gave informed consent to participate. The census method was used to determine the sample size.

\section{Management strategies}

Our management strategies for treatment and improvement of infertile women's QoL include: 1) holding yoga classes for infertile women; 2) holding educational classes for the families of infertile women for social support; and 3) quality management system in a long-term patient-centered treatment course in infertility centers.

\section{Questionnaire}

The study tool was a questionnaire made by the researcher. This questionnaire had four factors containing seven items, of which two were related to arranging yoga classes for infertile women, two to arranging educational classes for infertile women's families for social support, two to the quality management system in a long term patient-centered treatment course in infertility centers, and one item was related to prioritization of these three strategies by experts.

Questions based on the Likert scale (strongly agree, agree, disagree, disagree, strongly disagree), with a minimum score of 1 (worst condition) and a maximum score of 5 (best condition) for all questions, were distributed among all gynecologists. Experts in management strategies prioritized and scored the questionnaire. It should be noted that the alpha coefficient for the questionnaire was equal to 0.953 . The validity of the current questionnaire was measured by many academic members and researchers of the branch of 
Faculty of Health, Islamic Azad University, Tehran, Iran, using the content analysis method.

\section{Statistical evaluation}

All questionnaires were entered into the computer after ensuring the accuracy of data entry. Paired t test and Pearson correlation test were used for data analysis (SPSS 22.00). Values $P$ $<0.05$ were considered significant.

\section{RESULTS}

T he 59 specialist participants with an average age of $40.3 \pm 7.2$ had a working experience of 20 years or more $(47.8 \%), 15-20$ years $(32.2 \%), \quad 10-15$ years $(42.37 \%), 5-10$ years (15.25\%), and $1-5$ years (1.9\%). The majority of gynecologists participating in the study $(88.14 \%)$ agreed with all three management strategies, while $11.86 \%$ agreed with only the first and second ones. The first and third management strategies obtained the highest (86.44\%) and lowest (3.39\%) scores, respectively. Gynecologists scored each of the management strategies as listed in Table 1. Regarding the prioritization of management strategies, $64.41 \%$ of specialists believed that they should be used in the following order: first (1), second (2), and third (3) management strategy; and only $1.69 \%$ of them proposed a $3,1,2$ order. Thus, based on experts' opinions, the three management strategies were prioritized as shown in Table 2.

Using Pearson correlation test, there was a significant relationship between our management strategies and gynecologists' scoring $(P=0.010)$, which meant a significant relationship between these two variables with 95\% confirmation. Moreover, the independent t-test showed a significant relationship ( $\mathrm{P}=0.001)$ between the order of management strategies proposed in the present study and the prioritization provided of gynecologists. However, it had no significant relationship with their age and working experience $(\mathrm{P}>0.05)$.
TABLE 2. Frequency distribution of prioritization of management strategies by gynecologists in Sistan and Baluchestan province, Iran

\begin{tabular}{|l|l|}
\hline Prioritization & Frequency (\%) \\
\hline Management strategy 1,2,3 & $38(41 / 64)$ \\
\hline Management strategy 2,1,3 & $18(51 / 30)$ \\
\hline Management strategy 2,3,1 & $2(39 / 3)$ \\
\hline Management strategy 3,1,2 & $1(69 / 1)$ \\
\hline Management strategy 3, 2,1 & 0 \\
\hline Total & $59(0 / 100)$ \\
\hline
\end{tabular}

\section{DISCUSSION}

The first management strategy is yoga classes for infertile women. There are several types of yoga, including Asanas and Prayanamaya. In this method, soothing thoughts are taught at a deep level, which eliminates stress, improves the autonomic nervous system and controls emotions (11-13). The first management strategy obtained the highest score in our study. Oron et al found a significant difference in the QoL before and after yoga $(P=0.027)$. Stress and depression decreased too. This difference was also statistically significant $(P=0.0004)$. In another study (14), participants were divided into three groups (doing yoga in the classroom and under the supervision of an instructor, doing yoga at home, and control) and there was a significant difference in the QoL $(P<0.05)$ of the second group (yoga at home) compared to the control group. A study by Rahmani (15) found that after 12 weeks, the average total QoL score in the intervention group was significant compared to that of the control group and higher than before the intervention. Garg et al (16) showed that the overall QoL score before and after yoga exercise in the intervention group was significantly different $(P<0.001)$. In another study $(17)$, there was a significant reduction in anxiety in people

TA B LE 1. Frequency distribution of management strategies scored by gynecologists in Sistan and Baluchestan province, Iran

\begin{tabular}{|l|l|l|l|l|l|}
\hline Management strategies & Score 1 & Score 2 & Score 3 & Score 4 & Score 5 \\
\hline First management strategy & 0 & 0 & 0 & $8(56 / 13 \%)$ & $51(44 / 86 \%)$ \\
\hline Second management strategy & 0 & 0 & $1(69 / 1 \%)$ & $10(95 / 16 \%)$ & $48(36 / 81 \%)$ \\
\hline Third management strategy & 0 & 0 & $2(39 / 3 \%)$ & $25(37 / 42 \%)$ & $32(24.54 \%)$ \\
\hline
\end{tabular}


undergoing infertility treatment after six weeks of yoga compared to the control group $(P<0.014$ and $\mathrm{P}<0.001$, respectively). Therefore, this exercise can be used as an effective and low-cost method to improve infertile women's quality of life. It is recommended that healthcare providers should be trained in this field so that they should be able to use this method to promote health.

The second management strategy consists of holding educational classes for the families of infertile women to provide social support, which mainly means the help someone can get from the important people in his/her life in times of need. Studies show that people who get social support have more hope, are more successful in overcoming depression, and can easily adapt to physical disabilities, maintain self-dignity, and overcome loneliness. Also, according to evidence-based researches, people with a good support system are less likely to get sick and have low physiological stress levels (18). Thus, infertile women are less engaged in the social environment around them. Mongo et al showed that $83 \%$ of infertile couples were under pressure and stress due to their inability to have children while women and their parents experienced the highest stress level. In addition to professional psychological support during infertility treatment, women also express their need for support and sympathy from social groups (families, treatment groups and caregivers) (19). This study is consistent with the studies of Clara et al (18) and Friedlander et al (20) which assert that perceived social support, mental support, and life satisfaction in various aspects of an individual's life have many positive effects and are an effective moderating factor in coping with and adapting to stressful living conditions. However, these studies emphasized only the effect of social support in reducing anxiety. Family support as a management strategy has a significant positive impact on the mental health of the infertile person in critical situations $(18,20,21)$.

The third management strategy of quality management system in the long term is based on patient-centered treatment in infertility centers. Service quality management systems are considered important tools for quality improvement in various aspects. Patient-centered treatment is being raised as a global issue today and, according to the American Medical Institute, it is one of the key components of the quality of health care $(22,23)$. Patient-centered treatment means physicians interacting with patients. Based on this concept, the physician must fully know the patient. In different studies, various aspects of patient-centered treatments have been enumerated, but generally, of great importance is that the physician finds his way to the patient's world and observes the illness from the patient's perspective, thus planning the treatment process from the same perspective (24). In patient-centered care or individualistic care, physicians should be able to experience their patients' illness as the patient oneself does and tret him/her appropriately rather than just being beneficial to the patient. It is worth mentioning that there is no clear universal definition for patient-centered care $(25,26)$. Quality management in health care services is based on patient safety and effective treatment process (27). For this reason, patient's opinion is the most important indicator in quality assessments (28). A study by Creston et al showed that a professional quality management system could improve patient visits as well as the quality of clinical care (29). A study by Shaw et al has shown that accreditation by ISO was more effective in ensuring patients' safety and quality of services provided to them (30). In general, patient-centered treatment is one of the key components in the quality of medical services. Therefore, health care organizations must take steps in this direction by using appropriate methods (28).

\section{CONCLUSION}

The results of this study showed that the comprehensive management strategies in treating and improving infertile women's quality of life did not only reduce depression, anxiety and stress or help them achieve a better QoL, but also lead to a significant decrease of their depression and stress levels below the test cut point. Despite the benefits of the present study, it also had some limitations, just like other studies. It is also suggested that a similar study should be performed on infertile men.

Conflicts of interest: none declared.

Financial support: none declared.

Acknowledgments: The authors thank the hospital staff and management. 


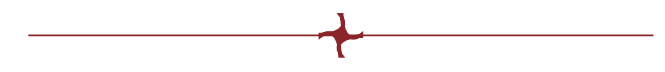

\section{$\mathbf{R}_{\text {EFERENCES }}$}

1. Hasanzadeh M, Akbari B, Abolghasemi A. Efficiency of Acceptance and Commitment Therapy on Psychological Well-being and Sexual Function in Women with Infertility History.

Avicenna Journal of Nursing and Midwifery Care 2019;27:250-259.

2. Mbizvo MT, Chou D, Shaw D. Today's evidence, tomorrow's agenda: implementation of strategies to improve global reproductive health. International Journal of Gynecology $\mathcal{E}$ Obstetrics 2013;121:S3-S8.

3. Taebi M, Simbar M, Abdolahian S. Psychological empowerment strategies in infertile women: A systematic review. Journal of Education and Health Promotion 2018;7.

4. Novak E. Berek \& Novak's Gynecology, Lippincott Williams \& Wilkins, 2007.

5. Qasemzadeh $\mathbf{N}$, et al. The comparative study of life style items between infertile and fertile couples at Urmia.

Nursing And Midwifery Journal 2019;17:463-472.

6. Jahromi BN, Mansouri M, Forouhari S, et al. Quality of life and its influencing factors of couples referred to an infertility center in Shiraz, Iran. International Journal of Fertility $\mathcal{E}$ Sterility 2018;11:293.

7. Hossein Rashidi B, Malek Afzali H, et al. The utilization of infertility services by infertile couples in Iranian infertility Clinics in 2012-2014.

The Iranian Journal of Obstetrics, Gynecology and Infertility 2017;20:1-12.

8. Ni $Y$, Tong $C$, Huang $L$, et al. The analysis of fertility quality of life and the influencing factors of patients with repeated implantation failure. Health and Quality of Life Outcomes 2021;19:1-10.

9. McKee M, Suhrcke M, Nolte E, et al. Health systems, health, and wealth: a European perspective. The Lancet 2009;373:349-351.

10. Mosadeghrad AM, Abbasi M. Managerial intelligence of hospital managers in Sari, Iran. Quarterly Journal of Management Strategies in Health System 2019.

11. Hussain A, Chandel RK, Ganie MA, et al. Prevalence of psychiatric disorders in patients with a diagnosis of polycystic ovary syndrome in Kashmir.
Indian Journal of Psychological Medicine 2015;37:66-70.

12. Yekkeh Fallah L, Azimi H, Sadeghi T. Comparison of the effects of two types of exercise on blood glucose levels and anti-diabetics tablets used by people with type II diabetes.

Iran Journal of Nursing 2014;27:79-87.

13. Nagendra H, Kumar V, Mukherjee S. Cognitive behavior evaluation based on physiological parameters among young healthy subjects with yoga as

intervention.

Computational and Mathematical Methods in Medicine 2015;2015 https://doi.org/10.1155/2015/821061

14. Wolff M, Sundquist K, Lönn SL, Midlöv P. Impact of yoga on blood pressure and quality of life in patients with hypertension-a controlled trial in primary care, matched for systolic blood pressure.

BMC Cardiovascular Disorders 2013;13:1-9.

15. Rahmani S, Zahirrodin A, Moradi M, et al. Examining the effectiveness of mindfulness-based stress reduction program and conscious yoga on quality of life in patients with diabetes type 2 . Iranian Journal of Diabetes and Obesity 2014;6:168-175.

16. Garg S, Ramya C, Shankar V, Kutty K. Efficacy of short-term Yoga therapy program on quality of life in patients with psychosomatic ailments. Indian Journal of Psychiatry 2015;57:78.

17. Jasani $S$, Heller $B$, Jasulaitis $S$, et al. Impact of a structured yoga program on anxiety in infertility patients: A feasibility study. JFIV Reprod Med Genet 2016;4:2014-2026.

18. Clara IP, Cox BJ, Enns MW, et al. Confirmatory factor analysis of the multidimensional scale of perceived social support in clinically distressed and student samples. Journal of Personality Assessment 2003;81:265-270.

19. Arjmandniya A, Afroz G, Nami M. Comparison of stress and marital satisfaction and perceived social support in parents of mental retard children and normal children on Golestan. especial training magazine [Article in Persian]. 2013;3:116.

20. Friedlander LJ, Reid GJ, Shupak N, Cribbie R. Social support, self-esteem, and stress as predictors of adjustment to university among first-year undergraduates. Journal of College Student Development 2007;48:259-274.

21. Tajalli $P$, Ganbaripanah A. The relationship between daily hassles and social support on mental health of university students.

Procedia-Social and Behavioral Sciences 2010;5:99-103.

22. Beholz S, Konertz W. Improvement in cost-effectiveness and customer satisfaction by a quality management system according to EN ISO 9001:2000. Interact Cardiovasc Thorac Surg 2005;4:569-573.

23. Dizaj AVT, Baniasadi A, Ezabadi Z, Kermani B. The Effect of Quality System Management on Patient Centeredness in an Infertility Care Center.

The Summer Supplement of Shefaye Khatam 1, 2015;3:53-62.

24. Saha S, Beach MC, Cooper LA.

Patient centeredness, cultural competence and healthcare quality. Journal of the National Medical Association 2008;100:1275-1285.

25. Mead N, Bower P. Patient-centredness: a conceptual framework and review of the empirical literature. Social Science \& Medicine 2000;51:1087-110.

26. Aarts J, Faber M, Van Empel I, et al. Professionals' perceptions of their patients' experiences with fertility care. Human Reproduction 2011;26:1119-1127.

27. Booth $M$, James $P$, Stevanovic V. Benchmarking of hospital activity data: an international comparison. Benchmarking: An International Journal 2005;12:512-522.

28. Kister A, editor. Descriptive and Indicator-Based Evaluation of Quality Management System in Medical Care Faciliities. $9^{\text {th }}$ International Quality Conference, 2015.

29. Korsten P, Sliwa B, Kühn M, et al. Impact of professional quality management on interdisciplinary emergency care units. European Journal of Emergency Medicine 2014;21:98-104.

30. Shaw C, Groene O, Mora N, Sunol R. Accreditation and ISO certification: do they explain differences in quality management in European hospitals? International Journal for Quality in Health Care 2010;22:445-451. 